\title{
In Vivo Visualization of Delta Opioid Receptors upon Physiological Activation Uncovers a Distinct Internalization Profile
}

\author{
Lauren Faget, ${ }^{1}$ Eric Erbs, ${ }^{1}$ Julie Le Merrer, ${ }^{1}$ Gregory Scherrer, ${ }^{2}$ Audrey Matifas, ${ }^{1}$ Nadia Benturquia, ${ }^{3}$ Florence Noble, ${ }^{3}$ \\ Marion Decossas, ${ }^{4}$ Marc Koch, ${ }^{5}$ Pascal Kessler, ${ }^{5}$ Jean-Luc Vonesch, ${ }^{5}$ Yannick Schwab, ${ }^{5}$ Brigitte L. Kieffer, ${ }^{1}$ \\ and Dominique Massotte ${ }^{1}$ \\ ${ }^{1}$ Translational Medicine and Neurogenetics, Institut de Génétique et de Biologie Moléculaire et Cellulaire, F-67404 Illkirch, cedex France, ${ }^{2}$ Department of \\ Physiology and Cellular Biophysics, Columbia University, New York, New York 10032, ${ }^{3}$ Neuropsychopharmacologie des Addictions, Université Paris \\ Descartes, Faculté de Pharmacie, Paris F-75010, France, ${ }^{4}$ Institut de Biologie Moléculaire et Cellulaire, F-67084 Strasbourg, France, and ${ }^{5}$ Imaging Center, \\ Institut de Génétique et de Biologie Moléculaire et Cellulaire, F-67404 Illkirch, France
}

G-protein-coupled receptors (GPCRs) mediate numerous physiological functions and represent prime therapeutic targets. Receptor trafficking upon agonist stimulation is critical for GPCR function, but examining this process in vivo remains a true challenge. Using knock-in mice expressing functional fluorescent delta opioid receptors under the control of the endogenous promoter, we visualized in vivo internalization of this native GPCR upon physiological stimulation. We developed a paradigm in which animals were made dependent on morphine in a drug-paired context. When re-exposed to this context in a drug-free state, mice showed context-dependent withdrawal signs and activation of the hippocampus. Receptor internalization was transiently detected in a subset of CA1 neurons, uncovering regionally restricted opioid peptide release. Importantly, a pool of surface receptors always remained, which contrasts with the in vivo profile previously established for exogenous drug-induced internalization. Therefore, a distinct response is observed at the receptor level upon a physiological or pharmacological stimulation. Altogether, direct in vivo GPCR visualization enables mapping receptor stimulation promoted by a behavioral challenge and represents a powerful approach to study endogenous GPCR physiology.

\section{Introduction}

G-protein-coupled receptors (GPCRs) mediate a host of physiological functions and represent a major target for therapeutic drugs. Stimulation of a GPCR, by natural or synthetic ligands, triggers receptor activation and phosphorylation, which enables $\beta$-arrestin recruitment and initiates receptor internalization. The latter event blunts G-protein-mediated signaling and favors activation of other intracellular effector pathways (Zheng et al., 2010). Internalization, therefore, is a critical process that strongly regulates receptor activity and signaling. Characterizing mechanisms of in vivo receptor trafficking, hence, represents a major goal in GPCR research.

\footnotetext{
Received Jan. 13, 2012; revised March 20, 2012; accepted March 21, 2012.

Author contributions: L.F. and D.M. designed research; L.F., E.E., J.L.M., A.M., N.B., Y.S., and D.M. performed research; G.S., F.N., M.D., M.K., P.K., J.-L.V., and Y.S. contributed unpublished reagents/analytic tools; L.F., E.E., J.L.M., Y.S., and D.M. analyzed data; L.F., B.L.K., and D.M. wrote the paper.

We wish to thank our funding sources including the Centre National de la Recherche Scientifique, the Institut National de la Santé et de la Recherche Médicale, the Université de Strasbourg, The Agence Nationale pour la Recherche (IMOP), the National Institutes of Health (NIDA DA-05010) and the Stefan and Shirley Hatos Center for Neuropharmacology. L.F. was a recipient of a region Alsace fellowship. We also wish to thank Yanina Giangreco and Emilie Rey for excellent technical assistance and Dr. Katia Befort for critical reading.

Correspondence should be addressed to Dominique Massotte, Department t of Translational Medicine and Neurogenetics, IGBMC (UMR7104, U964), 1 rue Laurent Fries BP 10142, F-67404 IIIkirch cedex, France. E-mail: massotte@igbmc.fr.

DOI:10.1523/JNEUROSCI.0185-12.2012

Copyright $\odot 2012$ the authors $\quad 0270-6474 / 12 / 327301-10 \$ 15.00 / 0$
}

Most of our current knowledge stems from cellular models involving recombinant GPCRs overexpressed in heterologous host cells or primary cell cultures. A limited number of studies have addressed native receptor internalization in primary neuronal cultures or brain sections, and very few have dealt with drug-induced in vivo trafficking in the brain (Decossas et al., 2003; von Zastrow, 2010; Enquist et al., 2011; He and Whistler, 2011; Henry et al., 2011). So far, GPCR internalization has been almost exclusively investigated under drug treatment. A major next step is now the depiction of receptor trafficking under physiological (endogenous ligand) rather than pharmacological (drug) stimulation. Currently available approaches do not allow the easy detection of native receptor trafficking and, to our knowledge, only two studies have addressed physiological receptor endocytosis, but none explored this process in the brain (Trafton et al., 2000; Jung et al., 2009).

Our laboratory recently developed knock-in mice expressing the delta opioid receptor, a class A GPCR, in fusion with the enhanced green fluorescent protein (DOR-eGFP), which enables direct in vivo visualization of the receptor with subcellular resolution (Scherrer et al., 2006). Using this unique tool, our first set of studies unambiguously established the in vivo relevance of receptor internalization for drug efficacy (Pradhan et al., 2009, 2010). Here, we took advantage of the DOR-eGFP mice to address delta opioid receptor internalization under physiological 
conditions by visualizing and characterizing delta opioid receptor activation upon endogenous opioid peptide release.

Along with a main role in the control of chronic pain and emotional responses (Filliol et al., 2000; Gavériaux-Ruff and Kieffer, 2002), delta opioid receptors are involved in spatial memory (Robles et al., 2003), and increasing evidence emphasizes their implication in drug-context associations using placepreference conditioning (Le Merrer et al., 2011) or reinstatement of drug-seeking paradigms (Ciccocioppo et al., 2002; Marinelli et al., 2009). The hippocampal formation is a critical brain structure for the processing of associative information embedded within a spatial context (Rudy, 2009). Since both delta opioid receptors and opioid peptides are expressed in the hippocampus, we hypothesized that a behavioral paradigm involving strong association between a drug of abuse and a specific environment would result in delta receptor activation in this limbic structure. Using fluorescent DOR-eGFP mice, we identified neuronal populations whose activity is spatiotemporally regulated upon mouse reexposure to a morphine-paired context and discovered that responsive neurons exhibit a subcellular distribution of intracellular DOR-eGFP that differs from internalization upon exogenous drug administration.

\section{Materials and Methods}

Animals

Knock-in mice DOR-eGFP, expressing delta opioid receptor coupled to a GFP, were generated by homologous recombination. In these mice, the eGFP cDNA was introduced into exon 3 of the delta opioid receptor gene in frame and 5' from the stop codon (Scherrer et al., 2006). DOR-eGFP mice were crossed with mu-opioid receptor-deficient mice (MOR-KO) to obtain mice expressing the DOR-eGFP protein but no mu opioid receptors. Wild-type mice were used for control. The genetic background of all mice was C57BL/6 J:129svPas (50:50\%). Mice were housed in a temperature- and humidity-controlled animal facility $\left(21 \pm 2^{\circ} \mathrm{C}, 45 \pm\right.$ $5 \%$ humidity) on a $12 \mathrm{~h}$ dark/light cycle with food and water ad libitum. Male and female mice aged $8-14$ weeks were used in all protocols. All of the experiments were conducted during the light period. All experiments were performed in accordance with the European Communities Council Directive of May 26, 2010, and approved by the local ethical committee (Com'Eth 2010-003).

\section{Drugs}

Morphine chlorhydrate (Francopia) was administered at doses of 5, 10, and $30 \mathrm{mg} / \mathrm{kg}$ (s.c.). Naloxone hydrochloride (Sigma) was used at 0.1, 0.3, 0.5, and $1 \mathrm{mg} / \mathrm{kg}$ (s.c.) for the pharmacological induction of morphine withdrawal. The enkephalinase inhibitor RB101 ( $N$ - $[(R, S)$-2-benzyl-3[( $S)(2-$ amino-4-methylthio)butyldithio]-1-oxopropyl]-L-phenylalanine benzyl ester) was a generous gift from F. Noble and was used at $60 \mathrm{mg} / \mathrm{kg}$ (i.p.). Lithium chloride ( $\mathrm{LiCl}$ ) (Sigma) was administered at a dose of $3 \mathrm{mEq} / \mathrm{kg}$ (i.p.). SNC 80 (Tocris Bioscience) was used at 0.3, 1, 3, and $10 \mathrm{mg} / \mathrm{kg}$ (s.c.). All drugs and compounds were administered at $10 \mathrm{ml} / \mathrm{kg}$ and dissolved in $\mathrm{NaCl}$ 0.9\% (solution used for control animals) except for RB101, which needed the addition of $10 \%$ Cremophor EL compound (Polyoxyl-35 castor oil) in $10 \%$ ethanol.

\section{Behavioral paradigms}

Paired drug-context paradigm. Experiments were performed in stable conditions: $21 \pm 2^{\circ} \mathrm{C}, 45 \pm 5 \%$ humidity, $40 \pm 2$ lux. Following $2 \mathrm{~d}$ of handling, animals received daily morphine $(30 \mathrm{mg} / \mathrm{kg}$, s.c.) or saline solution $(\mathrm{NaCl} 0.9 \%$, s.c.) injection for $6 \mathrm{~d}$ and were immediately placed in a Plexiglas transparent box $(30 \times 15 \times 15 \mathrm{~cm})$ with a mirror on one of its walls for $60 \mathrm{~min}(n=12)$. On the seventh day, mice were put back in this context after saline solution administration and the behavior was scored for $20 \mathrm{~min}$. We scored three categories of somatic signs of withdrawal: activity, anxiety-discomfort, and vegetative signs by $5 \mathrm{~min}$ period bins. Horizontal activity (scored from 0 to 2 ) and rearing (expressed as event numbers) were measured to characterize global activity. Scratches, genital licks, grooming, head shakes, wet dog shakes, paw tremors, sniffing (expressed as event numbers), and body tremors (absence or presence scored as 0 or 1 ) were measured as anxiety and discomfort signs. Finally, vegetative signs such as ptosis, piloerection, teeth chattering, and diarrhea were observed (absence or presence scored as 0 or 1, respectively). We established a global score of withdrawal that took into account the relative weight of each scored sign (Berrendero et al., 2003) and calculated this score for each mouse: (activity + rearing + grooming + genital licks + scratches + wet dog shakes $) \times 0.5+$ (jumps + paw tremors + sniffing $) \times 1+($ body tremors + ptosis + piloerection + teeth chattering + diarrhea) $\times 1$.

Unpaired drug-context paradigm. Mice daily received morphine (30 $\mathrm{mg} / \mathrm{kg}$, s.c., $n=13$ ) or saline injection (s.c., $n=10$ ) in their home cage and were randomly exposed to the test context $2 \mathrm{~h}$ before or at least $6 \mathrm{~h}$ after morphine administration. On the seventh day, animals were put back in this context after saline solution administration and behavior of the drug-free animals was scored for $20 \mathrm{~min}$.

Pharmacological withdrawal. Animals daily received morphine (30 $\mathrm{mg} / \mathrm{kg}$, s.c, $n=7-8$ ) or saline injection (s.c., $n=7-8$ ). On day 7, naloxone at $0.1,0.3,0.5$, or $1 \mathrm{mg} / \mathrm{kg}$ (s.c.) was injected $2 \mathrm{~h}$ after morphine or saline administration. Naloxone-induced withdrawal signs were then scored for $20 \mathrm{~min}$ and a global withdrawal score was determined as described above.

Enkephalinase inhibitor administration. RB101 (60 mg/kg, i.p.) was administered just before re-exposure to the context on the test day to saline and morphine-treated animals $(n=4)$ submitted to the paired drug-context protocol. No behavioral scoring was performed.

Paired LiCl-context association. Mice received daily $\mathrm{LiCl}(3 \mathrm{mEq} / \mathrm{kg}$, i.p., $n=5$ ) or saline solution injection (i.p., $n=3$ ) and were immediately placed in the Plexiglas transparent box for $60 \mathrm{~min}$. On day 7, animals were put back in the context after saline solution administration. No behavioral scoring was performed.

\section{Tissue preparation}

On the test day, mice were anesthetized $30,45,60,75$, or 90 min after re-exposure to the context with ketamine/xylazine $(100 / 10 \mathrm{mg} / \mathrm{kg}$, i.p.) and perfused intracardially with $10 \mathrm{ml}$ of $9.25 \%$ sucrose in phosphate buffer (PB) $0.1 \mathrm{M}, \mathrm{pH} 7.4$, followed by $50 \mathrm{ml}$ of $4 \%$ paraformaldehyde (PFA) (at $2-4^{\circ} \mathrm{C}$ ) in PB $0.1 \mathrm{M}$ or PBS $1 \mathrm{X}$ (Dulbecco's PBS, SigmaAldrich), $\mathrm{pH}$ 7.4. Brains were postfixed for $24 \mathrm{~h}$ at $4^{\circ} \mathrm{C}$ in $4 \%$ PFA solution, cryoprotected at $4^{\circ} \mathrm{C}$ in a $30 \%$ sucrose, $\mathrm{PB} 0.1 \mathrm{~m} \mathrm{pH} 7.4$ solution, embedded in Optimal Cutting Temperature medium (Thermo Scientific), frozen, and kept at $-80^{\circ} \mathrm{C}$. Brain sections were cut with a cryostat (CM3050; Leica) and kept floating in PB $0.1 \mathrm{M} \mathrm{pH} 7.4$ or mounted on SuperfrostTM glass (Menzel-Glaser) with Mowiol and 4',6-diamidino2-phenylindole (DAPI) 1:1000. For electron microscopy experiments, mice were anesthetized and intracardially perfused with $100 \mathrm{ml}$ of $4 \%$ PFA and $0.1 \%$ glutaraldehyde in cold PBS, then postfixed for $2 \mathrm{~h}$ in $4 \%$ PFA solution. One hundred micrometer thick brain sections were cut using a vibratome (Leica VT1000S).

\section{Immunohistochemistry}

c-fos detection. c-fos immunohistochemical detection was performed on $500 \mu \mathrm{m}$-thick free-floating sections using a standard avidin-biotin peroxidase method (Elite Vectastain Kit; Vector Laboratories). Peroxidase was detected with diaminobenzidine (Sigma). The primary antibody was a rabbit polyclonal antibody raised against the Fos protein (1/20,000, Ab5 anti-Fos; Oncogene Science). The secondary antibody was a biotinylated goat anti-rabbit IgG (1/2000; Jackson ImmunoResearch). c-fos labeling was performed on morphine-treated $(n=6)$ and saline-treated mice $(n=4)$ of the paired and unpaired protocols.

GAD65/67, parvalbumin, and phospho-DOR. Twenty micrometer cryostat sections were incubated in blocking solution (PB $0.1 \mathrm{~m} \mathrm{pH} \mathrm{7.4,5 \%}$ normal goat serum, and $0.2 \%$ Tween 20 ) for $2 \mathrm{~h}$ at room temperature (RT), then left overnight under shaking at $4^{\circ} \mathrm{C}$ with rabbit polyclonal primary antibodies raised against GAD65/67 (G5163, 1/2000; Sigma), rabbit polyclonal primary antibodies raised against the phosphorylated form of Serine 363 (anti-phospho-DOR, 1/100; Cell Signaling Technology), or mouse monoclonal primary antibodies directed against parval- 
bumin $(235,1 / 1000$; Swant) diluted in the blocking solution. After washes with PB $0.1 \mathrm{M} \mathrm{pH} 7.4$ and $0.2 \%$ Tween 20 , sections were incubated with Alexa Fluor 594-conjugated goat anti-rabbit secondary antibodies (GAR-alexa594) (A-11012, 1/2000; Molecular Probes) or Alexa Fluor 594-conjugated goat anti-mouse secondary antibodies (GAM-alexa594) (A-11005, 1/500; Invitrogen) for $2 \mathrm{~h}$ at RT. Phospho-DOR labeling was performed on mice administered with morphine and saline solution in the paired drug-context protocol, on naive mice, and on SNC80-treated mice $(10 \mathrm{mg} / \mathrm{kg}$ s.c., $30 \mathrm{~min})$ as a positive control.

\section{Image acquisition}

Samples were observed with an epifluorescence microscope (DM4000; Leica) using $10 \times$ numerical aperture (NA: 0.25), $20 \times(\mathrm{NA}: 0.7), 40 \times$ (NA:0.75), or $63 \times(\mathrm{NA}: 1.32)$ objectives zoom 1 or 0.55 with a CCD camera CoolSnap or with a confocal microscope (SP2RS; Leica) using $40 \times(\mathrm{NA}: 1.25)$ and $63 \times(\mathrm{NA}: 1.4)$ objectives zoom 1 or 4 with the LCS (Leica) software for image acquisition. Images for c-fos staining were acquired with the slide scanner NanoZoomer 2.0-HT (Hamamatsu) using a dry $20 \times$ objective (NA: 0.75 ).

\section{Counting protocol}

c-fos. c-fos-expressing cells were counted manually and blindly on images acquired using a Leica epifluorescence microscope $(10 \times$, zoom 0.55) or using the NDP viewer for slides scanned with the NanoZoomer 2.0-HT (Hamamatsu). Counting was performed in the three areas of the dorsal hippocampus (bregma: $-1.58 \mathrm{~mm}$ to -1.94 $\mathrm{mm}$ ); the dentate gyrus (DG), the Ammon's horn CA1 and CA3, in the basolateral amygdala (BLA) (bregma: $-0.82 \mathrm{~mm}$ to $-2.06 \mathrm{~mm}$ ), and in the paraventricular nucleus of the thalamus (PVT) (bregma: $-0.94 \mathrm{~mm}$ to $-2.06 \mathrm{~mm}$ ).

DOR-eGFP internalization. Total and internalized DOR-eGFP-expressing neurons were manually and blindly counted using a Leica epifluorescence microscope $(40 \times$ or $63 \times$, zoom 1$)$ in the DG (CA3 and CA1), the nucleus of the diagonal band (HDB; bregma: $0.62 \mathrm{~mm}$ to $-0.34 \mathrm{~mm}$ ), and the lateral part of the globus pallidus (LGP; bregma: $-0.22 \mathrm{~mm}$ to $-1.58 \mathrm{~mm}$ ). In the hippocampus, counting was done in the different layers in each area: stratum radiatum, stratum pyramidal, stratum oriens, and stratum oriens alveus for CA1 and CA3 and hilus, stratum granulosum, and stratum moleculare for DG. In total, 10-12 sections were counted per area and per animal, with four animals per group.

\section{Correlative light-electron microscopy}

Tissue preparation and immunohistochemical labeling. We used a correlative light-electron microscopy approach to identify the neuron of interest by GFP fluorescence in confocal microscopy and then used preembedding technique for electron microscopy to label DOR-eGFP in $100-\mu \mathrm{m}$-thick brain sections (Schikorski, 2010; Rezai et al., 2012). Sections were manually dissected into thin lamellae that were $\sim 100 \mu \mathrm{m}$ thick, $500 \mu \mathrm{m}$ wide, and $2 \mathrm{~mm}$ long and neurons of interest were localized with confocal microscope. Lamellae were first washed in glycine 150 mM PB 0.1 M solution, then washed three times for 5 min in HBS $1 \mathrm{X} \mathrm{pH}$ 7.4 (HBS: $154 \mathrm{~mm} \mathrm{NaCl}, 0.2 \mathrm{~mm} \mathrm{CaCl}_{2}$ and $20 \mathrm{~mm}$ HEPES-NaOH Sigma in $\mathrm{H}_{2} \mathrm{O} \mathrm{mQ}$ ) and permeabilized for $30 \mathrm{~min}$ in a $10 \%$ bovine serum albumin (BSA), $0.025 \%$ Triton X-100, HBS $1 \mathrm{X}$ pH 7.4 solution. Then, samples were incubated overnight at $4^{\circ} \mathrm{C}$ with the anti-GFP antibody (1/1000; Invitrogen) in 1\% BSA, 0.0025\% Triton X-100, HBS 1X pH 7.4 solution. After three washes of $5 \mathrm{~min}$ in $0.05 \%$ BSA and HBS $1 \mathrm{X}$ pH 7.4, samples were incubated overnight at $4^{\circ} \mathrm{C}$ in the secondary antibody, an anti-rabbit coupled to ultra-small immunogold particles $0.8 \mathrm{~nm}(1 / 200$; Aurion) diluted in $2 \%$ FSG, $1 \%$ BSA-c, $0.0025 \%$ Triton X-100, and HBS $1 \mathrm{X} \mathrm{pH} 7.4$ solution. After three washes of $5 \mathrm{~min}$ in HBS $1 \mathrm{X}$ pH7.4, samples were postfixed in $1 \%$ glutaraldehyde HBS $1 \mathrm{X} \mathrm{pH} 7.4$ solution for $10 \mathrm{~min}$. Lamellae were then washed two times for 5 min in HBS $1 \mathrm{X} \mathrm{pH} \mathrm{7.4}$ and three times for $5 \mathrm{~min}$ in $\mathrm{H}_{2} \mathrm{O}$ mQ before silver enhancement (gold particle raised to $10-15 \mathrm{~nm}$ ) for transmission electron microscope (TEM) observation. Samples were incubated with silver-enhancement reagents (R-Gent SE-EM; Aurion) for $40 \mathrm{~min}$ in a light-protected place and washed at least five times 5 to $10 \mathrm{~min}$ with $\mathrm{H}_{2} \mathrm{O}$ mQ to eliminate unfixed silver reagents. Samples were then postfixed in $0.5 \%$ osmium
$\left(\mathrm{OsO}_{4}\right)$ in $\mathrm{H}_{2} \mathrm{O}$ for 10 min to fix and contrast membranes. After three washes of $5 \mathrm{~min}$ in $\mathrm{H}_{2} \mathrm{O}$, lamellae were transferred in $2 \mathrm{ml}$ Eppendorf tubes for dehydration and embedding in epoxy resin for ultramicrotome cutting (Leica Ultracut UCT). Sixty nanometer ultrathin sections were observed with a Philips CM12 TEM operated at $80 \mathrm{kV}$. Images were acquired with an Orius 1000 CCD camera (Gatan).

Data analysis. Observation was restricted to neurons located in the first $2-5 \mu \mathrm{m}$ of the hippocampal lamellae for optimal antibody labeling. Two to three samples were analyzed per condition. Neurons of interest were recognized by correlation with confocal images. Axon terminals were identified by size (at least $0.2 \mu \mathrm{m}$ diameter) and the presence of numerous synaptic vesicles and mitochondria. Symmetric or asymmetric synapses were identified according to the presence of thin or thick postsynaptic specializations, respectively. The presence of labeled profiles was verified by examining serial tissue sections. Profiles were considered to be immunogold labeled when they contained one or more gold particles.

\section{Statistical Analysis}

Statistical analysis was performed with Graph-Pad Prism v4 (GraphPad) and Statistica v9 (StatSoft). Behavioral experiments and counting were analyzed using a Student's $t$ test (total scores), a one-way ANOVA (global score comparison with naloxone-induced withdrawal; number of DOReGFP internalized neurons in the CA1, CA3, and DG at different time points; at the $60 \mathrm{~min}$ time point in the three areas of the hippocampus; and in the CA1 at the $60 \mathrm{~min}$ time point in different conditions; fluorescence densities comparison), a two-way ANOVA (global scores comparison between paired and unpaired protocol, treatment $\times$ protocol; number of c-fos-expressing cells in the BLA and PVT, treatment $\times$ protocol), a two-way ANOVA with repeated measures (time course of behavioral scores, treatment $X$ time), and a three-way ANOVA (number of c-fos-expressing cells in the hippocampus, treatment $\times$ protocol $\times$ hippocampus area). Multiple comparisons were made using NewmanKeuls or Tukey's test for post hoc analysis.

\section{Results}

\section{Drug-context pairing induces withdrawal symptoms}

Based on previous literature, we established a paradigm involving measurable behavioral responses to drug-context association (Fig. 1A). DOR-eGFP mice were injected with morphine (30 $\mathrm{mg} / \mathrm{kg}$, s.c.) or saline for $6 \mathrm{~d}$ in an environment different from the home cage to induce association between drug effects and context where the drug was administered. On the test day, drug-free animals were re-exposed to this context and somatic signs of withdrawal were scored for $20 \mathrm{~min}$. Behavioral scores were classified in three categories: activity (horizontal activity and rearing), discomfort (grooming, scratches, genital licks and shakes), and vegetative signs (ptosis, teeth chattering, piloerection), and were scored in $5 \mathrm{~min}$ bin periods over a $20 \mathrm{~min}$ session (Fig. $1 \mathrm{~B}$ ). Morphine-treated animals showed increased horizontal activity during the first 10-15 min of the test then manifested discomfort and vegetative signs through the last $10 \mathrm{~min}$ compared with saline-treated mice. These animals exhibited a significantly higher global score than saline-treated mice (43.6 \pm 4.2 and $22.7 \pm 2.6$, respectively; $p=0.0001$ ) (Fig. $1 C$, paired drugcontext). Importantly, wild-type and DOR-eGFP mice showed similar context-induced behavior (Fig. $2 \mathrm{~A}$ ). This is in agreement with our previously published data indicating that eGFP fusion to delta receptor did not produce detectable alteration in mouse behavior (Scherrer et al., 2006; Pradhan et al., 2009).

To verify that the observed behavior indeed resulted from the association between drug administration and the context, we dissociated morphine injection from context presentation in a control experiment. Mice received daily morphine injections during $6 \mathrm{~d}$ in their home cage. In addition, presentation of the context was performed every day at random, but never at a time when 
A B

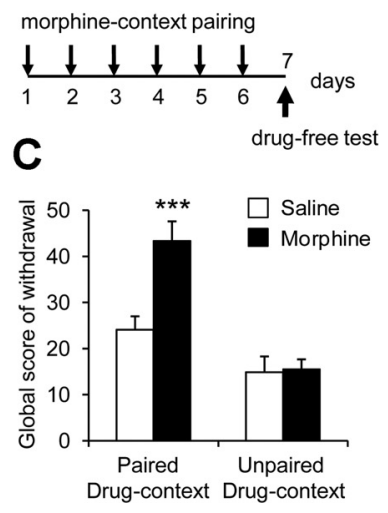

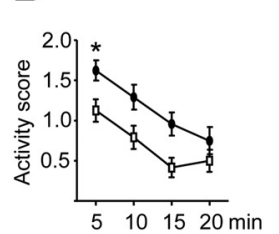
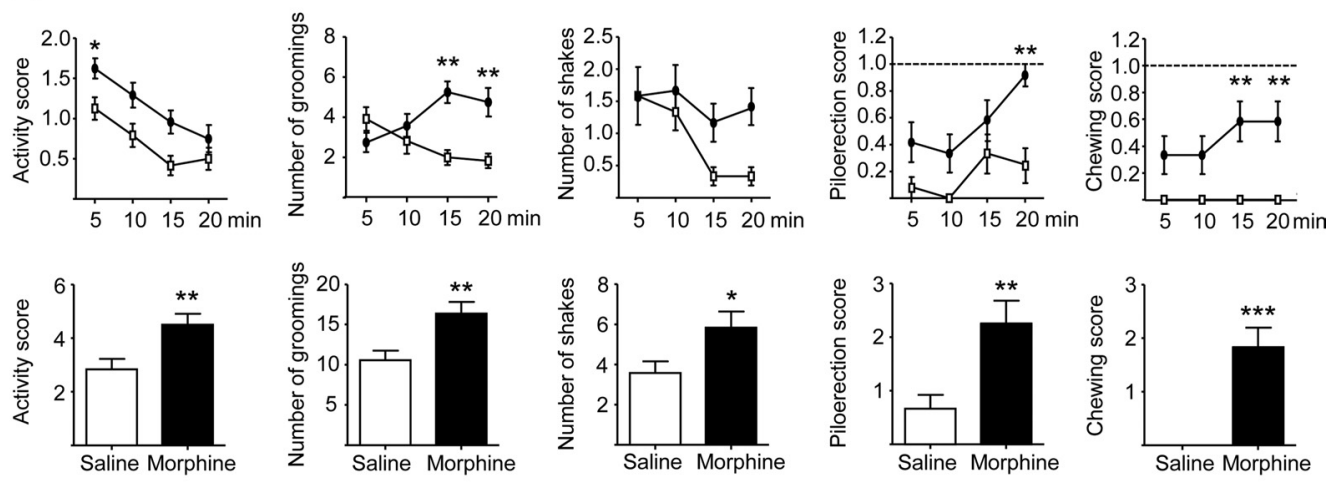
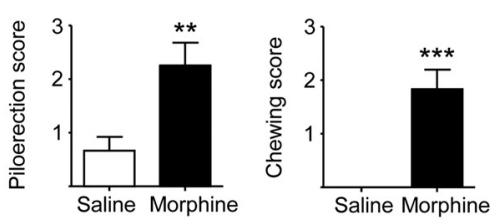

Figure 1. Re-exposure to drug-paired context induces withdrawal signs. $\boldsymbol{A}$, Drug-context pairing paradigm. D0R-eGFP mice received daily morphine (30 mg/kg, s.C.) or saline (NaCl 0.9\%, S.C.) injections for $6 \mathrm{~d}$, and were confined in a specific context for $60 \mathrm{~min}$ following injection. On the test day, mice received a saline injection and were re-exposed to the drug-associated context. Behavior was scored in $5 \mathrm{~min}$ bin periods for $20 \mathrm{~min}$. B, Scores of the most significant behavioral signs on test day. Left, Activity (horizontal activity). Middle, Signs of discomfort (grooming, head shakes and wet dog shakes).Right, Vegetative signs (piloerection and chewing). Total scores (bottom) were compared using a Student's $t$ test and time courses (top) were compared using a two-way ANOVA of repeated measures and a Newman-Keuls post hoc analysis. $n=12$. C, The global behavioral score was significantly higher in morphine-treated mice submitted to the paired protocol ( $n=12$ ) compared with saline-treated mice $(n=12)$. No difference was observed between morphine-treated $(n=13)$ and saline-treated ( $n=10)$ mice submitted to an unpaired protocol. Two-way ANOVA interaction of conditioning protocol (paired, unpaired) and drug treatment (morphine, saline): $F_{(1,42)}=10.12 ; p=0.0027 .{ }^{*} p<0.05 ;{ }^{* *} p<0.01 ;{ }^{* * *} p<0.001$ morphine versus saline.

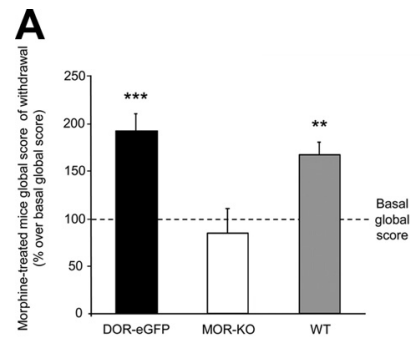

B

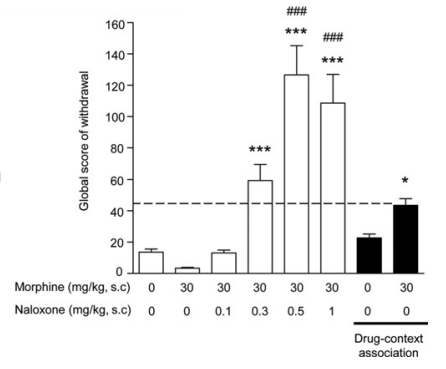

Figure 2. Context-induced withdrawal requires mu opioid receptor and compares to lowdose naloxone-precipitated withdrawal. $\boldsymbol{A}$, Withdrawal global score in DOR-eGFP, wild-type, and MOR-KO mice re-exposed to the drug-paired context. Each global score was compared with the basal global score of their saline counterpart (100\%). There is a general effect of the morphine treatment $\left(F_{(3,37)}=10,879 ; p<0.0001\right)$ but no difference is observed between morphine $(n=8)$ and saline $(n=6)$ mice deficient for mu opioid receptor submitted to the paired protocol ( $p=0.5278$ ). The global behavioral score is significantly higher in morphine-treated mice submitted to the paired protocol $(n=9)$ compared with saline-treated mice $(n=8)$ in wild-type animals (WT) $(p=0.0042)$ and in DOR-eGFP animals $(n=12)(p<0.001)$. There is no difference between global scores of withdrawal from WT and DOR-eGFP mice ( $p=$ $0.2749) .{ }^{* *} p<0.01$; ${ }^{* * *} p<0.001$; one-way ANOVA, comparison with saline global score. $\boldsymbol{B}$, Comparison between naloxone-precipitated and context-induced withdrawal after chronic morphine treatment. Pharmacological withdrawal precipitated by $0.3,0.5$, and $1 \mathrm{mg} / \mathrm{kg}$ naloxone induced significantly higher global behavioral scores in chronic morphine-treated mice $(6 \mathrm{~d}$, $30 \mathrm{mg} / \mathrm{kg}$, s.c.) $(n=8)$ compared with control animals $(n=8)$ (effect of the treatment $F_{(7.57)}$ $=29.57 ; p<0.001$ and Tukey's post hoc analysis: $p<0.001$ ). Mice chronically administered with morphine in the context (drug-context association protocol) also showed a higher global behavioral score than saline-injected animals $(p=0.018)$. This score was within the same range as scores observed for $0.3 \mathrm{mg} / \mathrm{kg}$ naloxone-precipitated withdrawal (dashed line) ( $p=$ 0.849). ${ }^{*} p<0.05$; ${ }^{* * *} p<0.001$; one-way ANOVA, comparison with saline-treated mice $0-0$ (pharmacological withdrawal); \#\#\# $p<0.001$; one-way ANOVA, comparison with morphinetreated mice 30-0 (drug-context association protocol).

mice were experiencing the pharmacological effects of morphine. Behavior of drug-free animals was scored on the test day, and was similar in both morphine- and saline-treated mice (unpaired drug-context group; $p=0.88$ ) contrasting with contextconditioned animals (paired drug-context group; $p=0.0001$ ) (Fig. 1C). In addition, mice deficient for the mu opioid receptor, the main molecular target for morphine, were tested in the paired drug-context protocol. As expected, the behavioral score was similar between drug- and saline-treated mice demonstrating that the morphine effect is entirely mediated via mu-receptor activation (Fig. 2 A). Finally, behavioral signs were also compared with those classically precipitated by the antagonist naloxone (Frenois et al., 2002). A dose-response curve using variable naloxone doses $(0.1,0.3,0.5$, and $1 \mathrm{mg} / \mathrm{kg})$ showed that re-exposure to the drug-paired context induced behavioral signs comparable to those induced by $0.3 \mathrm{mg} / \mathrm{kg}$ naloxone (43.6 \pm 4.2 and $59.4 \pm$ 10 , respectively), confirming that the context indeed induced a withdrawal syndrome similar to the well described naloxoneprecipitated withdrawal (Fig. $2 B$ ).

\section{Drug-context pairing leads to specific activation of the hippocampus}

We then investigated whether re-exposure to the drug-paired context promoted activation of the dorsal hippocampus, as would be anticipated from previous reports (see Introduction). Sixty minutes after re-exposure to the context, c-fos immediate early gene expression was significantly increased in CA1 and CA3 areas of morphine-dependent mice compared with their saline controls $(274.5 \pm 11.5$ vs $97.6 \pm 12.6$ in CA1; $p<0.0001$ and $181.5 \pm 7.4$ vs $94.5 \pm 3.8$ in CA $3 ; p<0.0001)$. No significant difference was detected between morphine- and saline-treated mice in the unpaired protocol. In addition, c-fos expression was significantly higher in morphine-dependent mice in paired compared with unpaired protocol $(274.5 \pm 11.5$ vs $119.2 \pm 14.7$ in $\mathrm{CA} 1 ; p<0.0001$ and $181.5 \pm 7.4$ vs $144.8 \pm 13.1$ in CA3, $p=$ 0.019 ) pointing again to the drug-context pairing specificity (Fig. $3 A, B)$.

We also examined c-fos expression in the BLA, a region involved in the control of emotional states as well as opiate reward (David et al., 2008). Higher c-fos expression levels were detected in morphine-treated animals in both paired and unpaired protocols (two-way ANOVA effect of the treatment $F_{(1,20)}=13.617$; $p=0.0014)$ with a significant increase in the paired protocol $(170.8 \pm 24.1$ vs $64.2 \pm 17.6 ; p=0.007)$ (Fig. $3 C)$. c-fos expression was also evaluated in the PVT, a control region that is not involved in memory processing or opiate reward. As expected, 
A

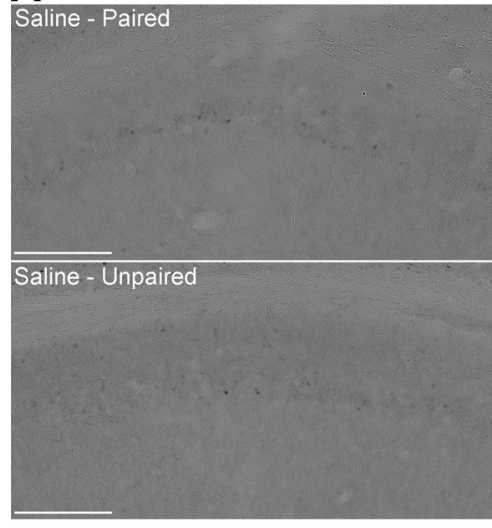

B

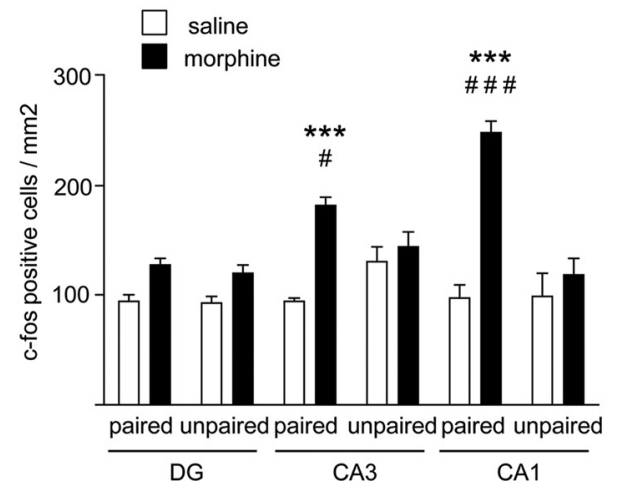

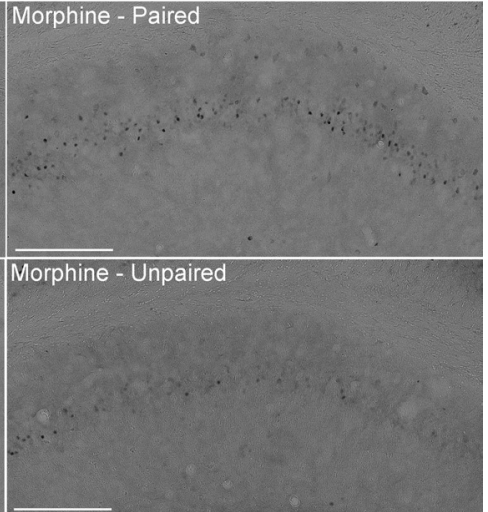

C

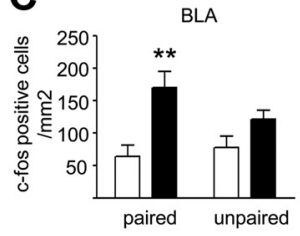

D

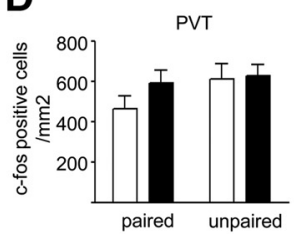

Figure 3. Re-exposure to drug-paired context induces c-fos expression in the hippocampus. $\boldsymbol{A}$, Brightfield photomicrographs of hippocampal CA1 c-fos labeling in different paradigms. Top, Paired conditioning (saline and morphine). Bottom, Unpaired conditioning (saline and morphine). Scale bar, $250 \mu \mathrm{m}$. B, Number of c-fos-expressing cells per millimeter squared in the three main areas of the hippocampus in morphine- and saline-treated mice in the paired or unpaired protocols. Three-way ANOVA analysis revealed an interaction between region ( $D G, C A 3, C A 1)$, conditioning protocol (paired, unpaired), and drug treatment (morphine, saline): $F_{(2,310)}=7.749 ; p<0.001$. Chronic morphine treatment $(30 \mathrm{mg} / \mathrm{kg}$ ) significantly increased the number of c-fos-positive cells in CA3 and CA1 regions re-exposed to the drug-paired context compared with saline-treated mice. No difference was observed between morphine- and saline-treated mice in the unpaired drug-context protocol. (saline $n=4$; morphine $n=6$ ). $C$, Chronic morphine treatment $(30 \mathrm{mg} / \mathrm{kg}$ ) also significantly increased the number of c-fos-positive cells in the BLA in animals re-exposed to the drug-paired context compared with saline-treated mice. D, Chronic morphine treatment $(30 \mathrm{mg} / \mathrm{kg})$ did not affect the number of c-fos-positive cells in the thalamic PVT used as a negative control region. ${ }^{* *} p<0.01 ;{ }^{* * *} p<0.001$ morphine versus saline; ${ }^{\#} p<0.05 ;{ }^{\# \#} p<0.001$ paired morphine versus unpaired morphine.

A

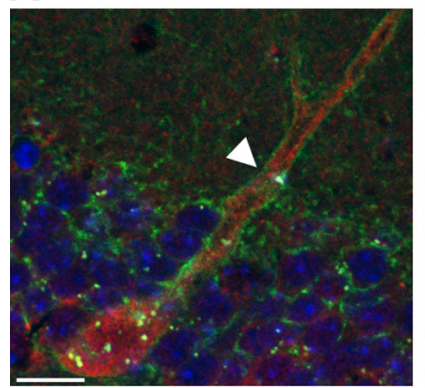

B

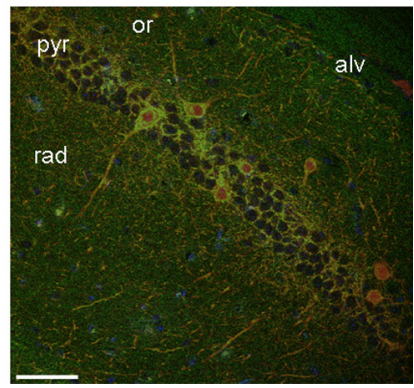

Figure 4. DOR-eGFP-expressing neurons in the CA1 are GABAergic neurons mainly coexpressing parvalbumin. $A$, D0R-eGFP-expressing neurons of the CA1 are GABAergic neurons. GABAergic neurons are detected with an anti-GAD65/67 antibody and visualized using Alexa Fluor 594-conjugated secondary antibodies. D0R-eGFP green fluorescence is visible at cell surface (arrowhead). B, DOR-eGFP-expressing neurons of the stratum oriens and stratum pyramidale are mostly parvalbumin-positive GABAergic interneurons (Alexa Fluor 594 fluorescence). Rad, stratum radiatum; pyr, stratum pyramidale; or, stratum oriens; alv, stratum oriens alveus. Confocal fluorescence photomicrographs in $20-\mu \mathrm{m}$-thick brain sections. Scale bars: $\boldsymbol{A}, 10 \mu \mathrm{m}$; B, $50 \mu \mathrm{m}$. c-fos expression level in the PVT remained unaffected in the different experimental paradigms (Fig. 3D).

\section{Re-exposure to the context promotes hippocampal DOR-eGFP activation} Drug-free re-exposure to the context represents a physiological situation that entails memory processes and triggers hippocampal activation. Accordingly, we postulated that endogenous opioid peptide release in this structure would stimulate delta receptors. Hence, we analyzed receptor cellular distribution throughout the hippocampus in DOR-eGFP mice that had experienced context-induced withdrawal and also examined receptor phosphorylation as an index of stimulation.

We first determined the mean number of DOR-eGFP-expressing neurons in the CA1, CA3, and DG areas of the dorsal hippocampus per $20 \mu \mathrm{m}$-thick section. Values ranged from $9.6 \pm 0.2$ in the $\mathrm{DG}$ to $21.0 \pm 0.4$ in the CA3 and $27.6 \pm 0.6$ in the CA1 region. All DOR-eGFP-expressing cells were GABAergic neurons and mainly coexpressed parvalbumin, a calcium binding peptide (Fig. 4). On the test day, a time course was performed to detect DOR-eGFP internalization in the hippocampus. Animals were killed 30, 45, 60, and 75 min after re-exposure to the context and the number of neurons showing internalized DOR-eGFP fluorescence was determined. Internalization patterns were detected in hippocampal neurons from morphine-treated mice but not saline controls. Maximal internalization was observed after $60 \mathrm{~min}$ in the three areas of the hippocampus (Fig. 5A-C) and was significantly higher in the CA1 compared with the CA3 and DG (Fig. 5D). In the CA1, internalization represented $\sim 9 \%$ of the total number of DOR-eGFP-expressing neurons (2.4 over 27.6 per 20 - $\mu$ m-thick section), whereas in the CA3 and DG regions values were $\sim 4 \%$ ( 0.8 over 21.0 and 0.4 over 9.6 per $20-\mu$ m-thick section respectively; $p<0.0001$ ) (Fig. 5D).

Colocalization by immunohistochemistry with markers specific for different GABAergic populations revealed that internalization within the CA1 $(88.9 \pm 3.8 \%)$ mostly took place in parvalbumin-positive neurons from the stratum oriens and stratum pyramidale (Fig. 6A). These neurons were previously identified as basket and chandelier cells that make direct postsynaptic contacts with glutamatergic principal cells (Mátyás et al., 2004; Klausberger and Somogyi, 2008).

We also examined DOR-eGFP internalization in other brain regions. In the LGP, whose activity is directly related to locomotor activity, DOR-eGFP was internalized in $>95 \%$ of the neurons in saline as well as in morphine-treated animals indicating tonic endogenous peptide release in this region (Fig. $6 \mathrm{~B}$ ). In contrast, no internalization was ever observed in the nucleus of the $\mathrm{HDB}$, a region projecting on the hippocampal structure (Fig. 6C). 
Several control experiments were then designed to confirm that DOR-eGFP internalization in the hippocampus was specifically related to drug-context pairing (Fig. 6D). No DOR-eGFP internalization was detected in morphine-treated mice in the unpaired drug-context protocol, establishing the requirement for an association between morphine administration and a given context. Also, DOR-eGFP did not internalize in conditions that did not induce physical dependence such as (1) mice treated with a single dose of morphine $30 \mathrm{mg} / \mathrm{kg}$ or (2) chronically treated for $6 \mathrm{~d}$ with low morphine doses $(5 \mathrm{mg} / \mathrm{kg}$ or $10 \mathrm{mg} / \mathrm{kg}$ ) and (3) mice deficient for mu opioid receptors chronically treated with morphine $30 \mathrm{mg} / \mathrm{kg}$. Finally, no DOR-eGFP internalization was observed after drug-context pairing when animals were under morphine ( $5 \mathrm{mg} / \mathrm{kg}$ or $30 \mathrm{mg} / \mathrm{kg}$ ) on the test day. In parallel, a group of mice was subjected to place conditioning to the aversive compound LiCl. DOR-eGFP internalization was also detected in the CA 1 and $\mathrm{CA} 3$ regions of the hippocampus, but its extent was significantly lower in the CA1 compared with the morphine-paired protocol $(0.8 \pm 0.2$ or $3 \%$ vs $2.4 \pm 0.4$ or $9 \%$, respectively; $p<0.001)$.

Last, to confirm that the DOR-eGFP receptor was indeed activated under endogenous stimulation, we examined receptor phosphorylation by immunohistochemistry. GPCR phosphorylation upon agonist binding is a well established step toward receptor internalization in heterologous cell systems. For the delta opioid receptor, serine 363 was reported as a major phosphorylation site (Kouhen et al., 2000). Hence, we used antibodies raised against the phosphorylated form of this serine residue (PSer363) to label hippocampal sections from DOR-eGFP mice $60 \mathrm{~min}$ after re-exposure to the context. Neurons showing internalized DOR-eGFP fluorescence were labeled with the PSer363 antibody. The signal appeared located intracellularly, indicating that internalized receptors were phosphorylated (Fig. 7). In a control experiment, mice treated for $30 \mathrm{~min}$ with the delta agonist SNC80 (10 mg/kg, s.c.) also showed colocalization of PSer363 immunostaining with DOR-eGFP fluorescence in endosomal vesicles (data not shown; Pradhan et al., 2009). On the other hand, saline-treated mice showed the DOR-eGFP signal mainly at the cell surface with no detectable PSer363 staining (data not shown). Thus, pharmacological or physiological stimulation both promote in vivo endocytosis of a phosphorylated form of the receptor. Altogether these data demonstrate
that re-exposure to the drug-paired con-
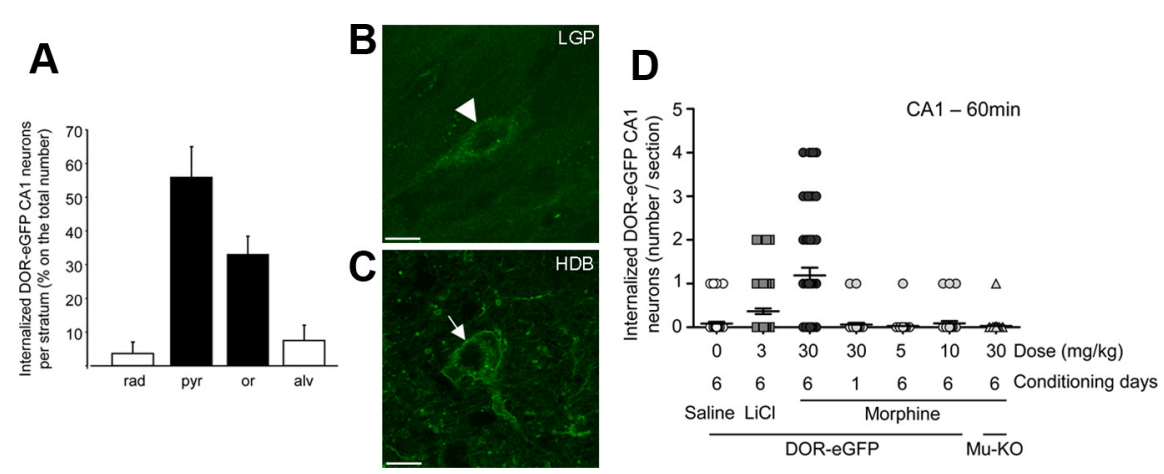

Figure 6. DOR-eGFP internalization in the CA1 parvalbumin-positive GABAergic neurons is specific to re-exposure to the drugpaired context. $\boldsymbol{A}$, There are $88.9 \pm 3.8 \%$ of the internalized DOR-eGFP neurons located in the stratum pyramidale (pyr) and stratum oriens (or) (dark bars; $10-12$ sections/animal; $n=4$ ). Rad, stratum radiatum; pyr, stratum pyramidale; or, stratum oriens; alv, stratum oriens alveus. $\boldsymbol{B}, \boldsymbol{C}$, Representative images from confocal fluorescence micrographs of DOR-eGFP-expressing neurons in control regions. $\boldsymbol{B}$, DOR-eGFP was internalized in almost all neurons of the LGP and in all of the tested conditions including morphine, saline, and paired and unpaired groups (arrowhead). $\boldsymbol{C}$, In the HDB, DOR-eGFP did not internalize and fluorescence remained at the cell surface (arrow). Scale bar, $10 \mu \mathrm{m}$. D, DOR-eGFP internalization in the dorsal CA1 after re-exposure to the context (60 min) was higher in morphine-treated mice submitted to the drug-paired context compared with all other control conditions $(10-12$ sections/animal; $n=4)$. Control groups included saline-conditioned (open circles) and LiCl-conditioned animals (gray squares), and one day-conditioning or lower morphine doses (gray circles) as well as mu-opioid receptor knock-out mice (Mu-KO) (gray triangles).
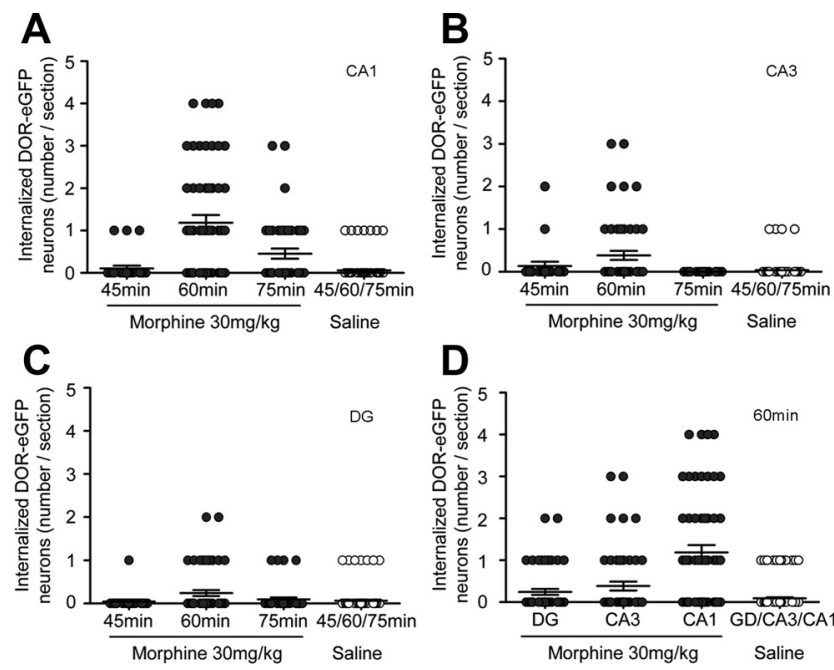

Figure 5. DOR-eGFP internalization is mainly detectable in the dorsal CA1 area of the hippocampus upon re-exposure to the drug-paired context. Time course of DOR-eGFP internaliza-

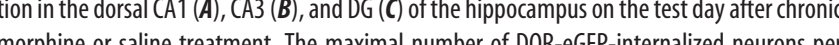
section was observed $60 \mathrm{~min}$ after re-exposure to the drug-paired context in morphine-treated mice ( $10-12$ sections/animal; $n=4)$. D, DOR-eGFP internalization in morphine-treated mice was higher in the CA1 compared with the $C A 3$ and DG areas after re-exposure for 60 min to the drug-paired context (10-12 sections/animal; $n=4$ ) Dark circles, morphine-treated mice; open circles, saline-treated mice.

\section{.} text resulted in receptor activation and endocytosis, which were detectable in DOR-eGFP mice. Monitoring receptor internalization in fluorescent knock-in mice is therefore an innovative and sensitive approach used to characterize GPCR activation in response to a physiological stimulation and map neuronal populations affected by endogenous peptide release.

\section{Physiological DOR-eGFP activation results in a specific internalization pattern}

Our previous studies showed that in vivo or ex vivo pharmacological activation of DOR-eGFP by the delta agonist SNC80 pro- moted receptor internalization in endoplasmic vesicles and subsequent targeting to lysosomes. High doses of SNC80 (3 and $10 \mathrm{mg} / \mathrm{kg}$ ) induced massive internalization, resulting in complete disappearance of the fluorescent signal from the cell surface and emergence of abundant bright intracellular vesicles. In contrast, low doses of SNC80 (0.3 and $1 \mathrm{mg} / \mathrm{kg})$ failed to produce any detectable internalization and DOR-eGFP fluorescence remained located at the plasma membrane (Scherrer et al., 2006; Pradhan et al., 2009). No intermediate pattern that would be distinct from all-or-no internalization could be observed (data not shown). 
A

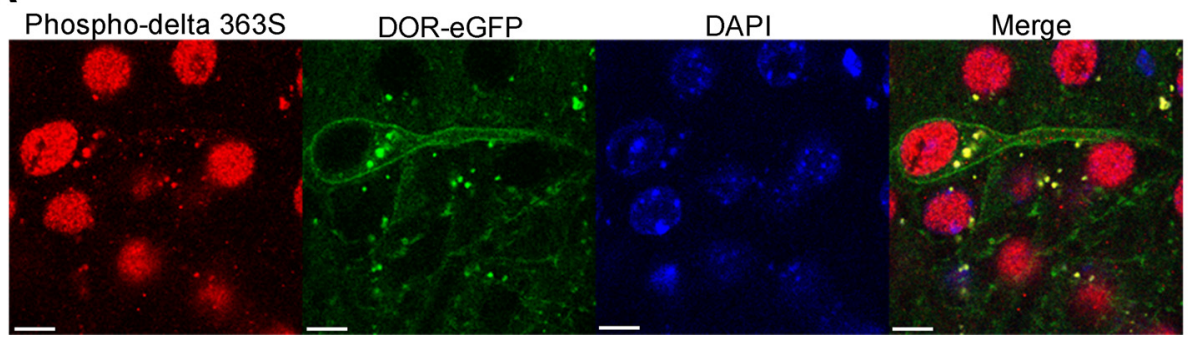

B

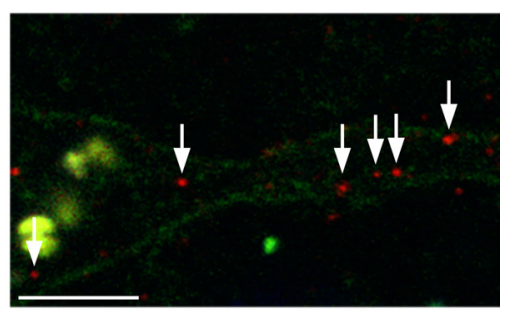

Figure 7. DOR-eGFP is phosphorylated upon re-exposure to the drug-paired context. Representative confocal micrographs showing DOR-eGFP internalization (green signal) and delta opioid receptor phosphorylation (red signal) as revealed with an anti-phospho-delta Serine363 antibody detected with an Alexa Fluor 594 -conjugated secondary antibody. Nuclei were stained with DAPI (blue). Context-exposed morphine-treated mice (60 min) resulted in colocalized intracellular DOR-eGFP and phospho-delta 3635 antibody staining (white arrows). $\boldsymbol{A}$, low magnification; $\boldsymbol{B}$, high magnification. Scale bar, $10 \mu \mathrm{m}$.

A
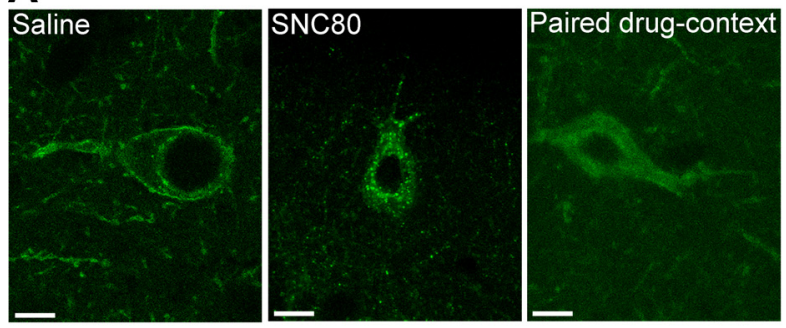

B

C
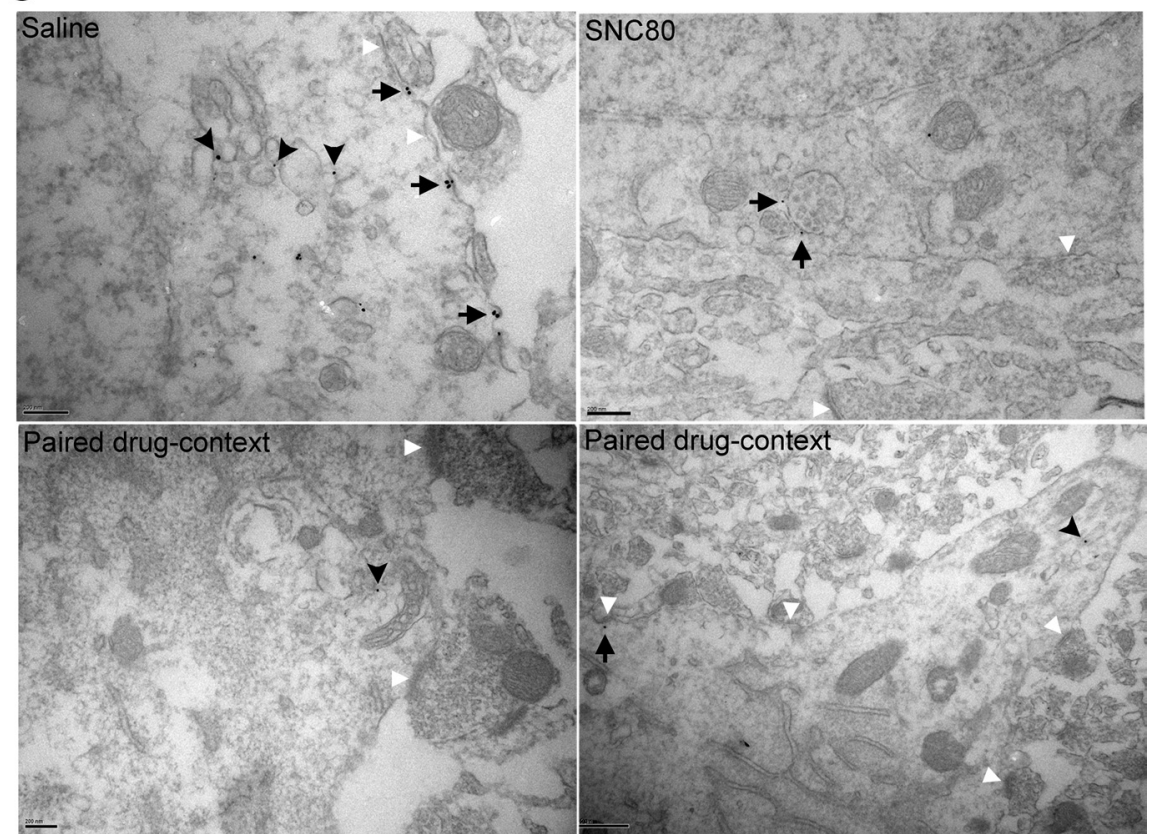

Paired drug-context
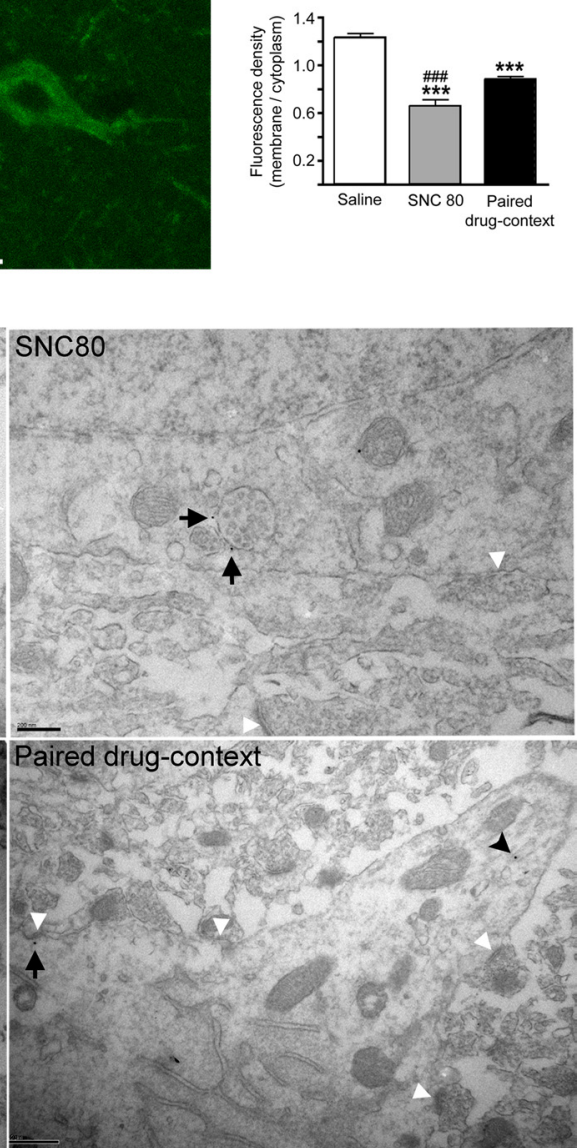

Figure 8. DOR-eGFP internalization differs from the classical drug-induced internalization pattern. $\boldsymbol{A}$, Representative confocal fluorescence micrographs of DOR-eGFP-expressing neurons in $20-\mu \mathrm{m}$-thick brain sections. In saline control mice (saline), DOReGFP fluorescence remained located at the membrane (left). In mice treated with the delta opioid agonist SNC80 (SNC80; 10 $\mathrm{mg} / \mathrm{kg}$, s.C., $30 \mathrm{~min}$ ), DOR-eGFP was entirely located in intracellular vesicles forming the classically described endosomal punctuate pattern (middle). In morphine-treated mice re-exposed to the context (paired drug-context, 60 min), DOR-eGFP fluorescence increased inside the cell and appeared as an almost homogenous diffuse staining. Some fluorescence remained present at the plasma membrane (right). Scale bar, $10 \mu \mathrm{m}$. B, Quantification of DOR-eGFP internalization expressed as a ratio of membraneassociated versus cytoplasmic fluorescence densities $(n=11)$. ${ }^{* * *} p<0.001$ compared with saline; ${ }^{\# \#} p<0.001$ SNC80-treated versus paired drug-context. C, Correlative light-electron microscopy. Images are representative micrographs showing eGFP immunolabeling in DOR-eGFP-expressing neurons. In saline-treated animals (saline), DOR-eGFP was located at the cell surface (black arrows) and in the Golgi apparatus (black arrowheads). In SNC80-treated animals (SNC80; $10 \mathrm{mg} / \mathrm{kg} \mathrm{s.C.,} 60 \mathrm{~min}$ ) DOR-eGFP was present on multivesicular bodies (black arrows). Sixty minutes after re-exposure to the context previously associated with morphine (paired drug-context), DOR-eGFP was identified on intracellular vesicles close to synapses in both cell bodies and dendrites of neurons (black arrowheads) and was also present at the cell surface (black arrow). Scale bars, $200 \mathrm{~nm}$, except bottom right panel, $500 \mathrm{~nm}$. White arrowheads: synaptic boutons.
In this study, DOR-eGFP internalization appeared very different from that observed upon pharmacological stimulation. Fluorescence intensified intracellularly in an almost homogenous manner throughout cell body. Additionally, a substantial amount of fluorescence still remained at the plasma membrane (Fig. $8 A, B)$. No recognizable endocytic vesicles could be identified as classically reported for GPCRs in cellular models or as observed following SNC80 administration in DOR-eGFP mice. Physiological DOReGFP internalization therefore appeared distinct from pharmacological sequestration and, remarkably, remained partial.

We then used the correlative lightelectron microscopy approach that we previously developed to accurately determine intracellular DOR-eGFP localization using anti-GFP antibodies (Fig. 8C) (Rezai et al., 2012). In saline-treated animals, the receptor was detected both at the plasma membrane and in the Golgi compartment. In morphine-treated animals re-exposed to the drug-paired context, DOR-eGFP remained in part located at the plasma membrane but was also associated to intracellular vesicles in close vicinity to synapses. This distribution was different from that observed upon treatment with the agonist SNC80. In the latter case, DOReGFP was detected in multivesicular bodies that belong to the degradation pathway, consistent with the previously described lysosomal targeting in primary cultures (Pradhan et al., 2009). Delta receptor intracellular distribution therefore appears different between endogenous or exogenous stimulation conditions. The pattern observed here likely reflects limited receptor activation upon local peptide release elicited by the behavioral challenge.

DOR-eGFP internalization is promoted by endogenous enkephalin release To verify that this novel pattern was indeed promoted by endogenous opioid 

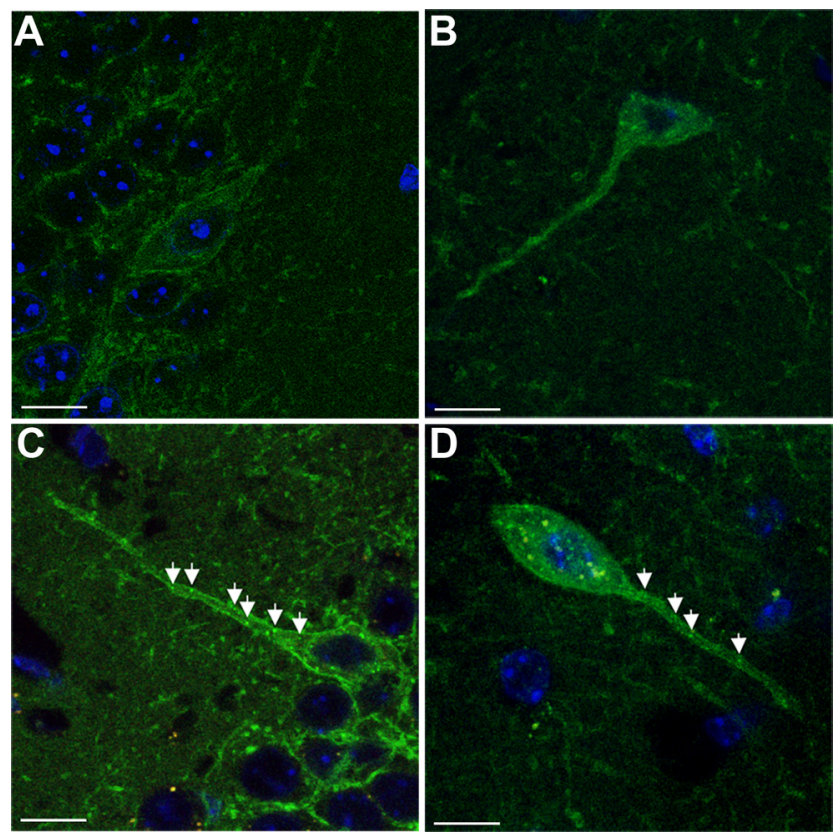

Figure 9. Enkephalin release is responsible for DOR-eGFP internalization. The enkephalinase inhibitor RB101 (60 mg/kg, i.p.) was administered immediately before re-exposure to the drugpaired context on the test day. $\boldsymbol{A}$, In saline-treated mice, RB101 did not modify DOR-eGFP cell membrane distribution. $\boldsymbol{B}$, In morphine-treated mice receiving saline solution, DOR-eGFP intracellular signal intensified as previously observed (Fig. 8). C, D, In morphine-treated mice that received RB101, D0R-eGFP fluorescence was still present at the membrane, but was also detected in intracellular vesicles similar to those observed after SNC80 treatment (arrows). Representative D0R-eGFP-expressing neurons in the CA1 stratum pyramidale $(\boldsymbol{C})$ and stratum oriens $(\boldsymbol{D})$ are shown. Nuclei were stained with DAPI (blue). Scale bar, $10 \mu \mathrm{m}$.

release, we performed a microdialysis experiment to quantify levels of Met- and Leu-enkephalin in the CA1 after re-exposure to the drug-paired context. Amounts of extracellular peptides, however, remained too low for detection by radioimmunoassay (data not shown). In a second set of experiments, we addressed Metenkephalin release using an immunohistochemical approach. Met-enkephalin was present in the CA1 30 and 45 min after morphine-treated animals were re-exposed to the drug-paired context, whereas no peptide could be detected in saline-treated animals re-exposed to the context (data not shown). To further confirm that enkephalin release was indeed responsible for DOReGFP internalization in our paradigm, we administered the enkephalinase inhibitor RB101 before context re-exposure to increase extracellular enkephalin levels (Noble et al., 2008). In saline-injected mice, RB101 treatment did not modify the localization of DOR-eGFP fluorescence (Fig. 9A). In contrast, RB101 influenced the internalization pattern of morphine-treated animals re-exposed to the context (Fig. $9 B-D$ ). Bright intracellular vesicles that resembled those observed upon SNC80 activation were detectable in RB101-treated animals. Also, whether RB101 was present or not, DOR-eGFP fluorescence was still detectable at the cell surface, indicating that internalization remained partial. These observations establish that local enkephalin release indeed promotes DOR-eGFP internalization in our paradigm. In addition, this experiment shows that artificial increase of endogenous enkephalin levels shifts receptor sequestration toward a pharmacological-like pattern.

\section{Discussion}

In this report, we visualized in vivo internalization of a native GPCR under behavioral challenge. We developed a paradigm involving strong association between morphine effects and a specific environment, so that re-exposure of drug-free animals to the drug-paired context elicited behavioral signs of withdrawal. Under those conditions, DOR-eGFP knock-in mice showed activation of the hippocampus with concomitant receptor phosphorylation and internalization. The methodological approach proved highly sensitive, since DOR-eGFP internalization could be detected in a small subset of neurons. Importantly, the internalization pattern evoked by endogenous opioid release was distinct from endocytosis patterns previously described upon pharmacological application.

In our paradigm, experimental conditions were implemented so that drug-free animals showed somatic signs of morphine withdrawal, which is consistent with previous reports of contextinduced signs of morphine withdrawal in rats (Taubenfeld et al., 2010). At the time of context presentation, animals were morphine dependent, as verified by naloxone-precipitated withdrawal in a parallel experimental group. Withdrawal signs that we scored upon re-exposure to the context were similar to those reported for a low dose of naloxone (Frenois et al., 2005) in both frequency and intensity, suggesting that animals experienced discomfort and anxiety attributable to negative motivational components of opiate withdrawal (Frenois et al., 2005). Further, animals re-exposed to the morphine-paired context showed increased $c$-fos expression in the CA1 and CA3 areas of the dorsal hippocampus, in agreement with the increased hippocampal c-fos expression described in previous place-conditioning studies using various appetitive drugs (Rademacher et al., 2007; Pascual et al., 2009). Altogether, we successfully established a behavioral situation where DOR-eGFP mice undergo a context-dependent aversive experience recruiting the hippocampal circuitry.

Internalized DOR-eGFP fluorescence colocalized with PSer363 antibody staining, indicating that delta opioid receptors were activated upon context-induced withdrawal. At this stage, the functional significance of endogenous receptor stimulation remains open. DOR-eGFP mice were conditioned to morphine at a dose-inducing physical dependence, and experienced a negative emotional state upon context exposure. Interestingly, DOReGFP internalization was also detectable following aversive place conditioning to $\mathrm{LiCl}$, although to a lesser extent, and in both cases, animals were exposed to the context under a drug-free state. Under those conditions, activation of CA1 neurons is consistent with the proposed role of the CA1 area as a coincidence detector (Martin and Clark, 2007), and reflects association of the context with strong emotional stimuli of positive or aversive value. Therefore, and in line with results showing delta receptor involvement in spatial learning and drug-context associations (Robles et al., 2003; David et al., 2008; Marinelli et al., 2009; Le Merrer et al., 2011), activation of delta opioid receptors in CA1 neurons may contribute to behavioral responses elicited by the drug-paired context, including possibly drug craving and drug-seeking behavior.

Examination of DOR-eGFP cellular distribution in two other control brain regions confirmed that delta receptor internalization in the CA1 area was specifically associated to the context challenge. In the LGP, receptor endocytosis was detected in all experimental groups (morphine/saline, paired/unpaired) and occurred in almost all DOR-eGFP-positive neurons. This region expresses high levels of Met-enkephalin and is involved in locomotor function; therefore the observed tonic activation of delta opioid receptor may reflect general animal activity across all experimental conditions. In contrast, no internalization was observed in the diagonal band of Broca, a region of high delta 
receptor density that is part of the hippocampo-septal formation and projects to the DG, suggesting a lack of basal delta receptor activity in this brain structure. Overall the possibility of characterizing stimulus-dependent and -independent DOR-eGFP internalization across distinct brain regions and map nonresponsive neurons definitely underscores the sensitivity of our detection method.

Several lines of evidence concur to indicate that DOR-eGFP internalization results from enkephalin release in our study. First, animals were drug free at the time of analysis. Further, the only drug used throughout experiments was morphine, acting at mu but not delta receptors under our conditions (Fig. 6D). Second, Met-enkephalin was detected in the CA1 area 30 and 45 min after re-exposure to the context and maximal receptor internalization was observed 30 min later, which is consistent with the kinetics previously described in response to agonist stimulation. Third, treatment with the enkephalinase inhibitor RB101 before reexposure to the context modified the internalization profile and intracellular vesicles appeared, similar to those observed upon addition of exogenous opiates. This is consistent with previous reports indicating that the aminopeptidase $\mathrm{N}$ inhibitor increases local peptide concentration (Noble et al., 2008). Finally, other studies have shown that morphine treatment modulates enkephalin levels. Expression of Leu- and Met-enkephalin was increased in the hippocampus during chronic morphine administration (Nylander et al., 1995; Tejwani and Rattan, 1997), and levels of aminopeptidase $\mathrm{N}$ were decreased during morphine withdrawal (Irazusta et al., 2003). Thus, DOR-eGFP internalization characterized in this study indeed reflects physiological stimulation of the receptor.

Importantly, the internalization pattern evoked by context presentation strikingly differed from what was observed upon pharmacological activation (Scherrer et al., 2006; Pradhan et al., 2009). Using DOR-eGFP knock-in mice, we previously showed that systemic administration of alkaloid (SNC80) or peptidic (Met-enkephalin, deltorphin II) agonists triggered complete depletion of the DOR-eGFP signal from the cell surface, together with formation of bright fluorescent intracellular vesicles both in vivo and ex vivo (Scherrer et al., 2006; Pradhan et al., 2009, 2010). Here, endogenous stimulation produced only partial depletion of surface DOR-eGFP fluorescence and no endosomal vesicles could be observed. Retention of GFP fluorescence at the plasma membrane reflected partial internalization of the surface receptor pool that is consistent with receptor activation by endogenous peptide release restricted to synaptic regions and limited in time by protease degradation. We thus propose that this novel pattern characterizes physiological conditions and results from a locally and spatially restricted activation of the receptor.

Because the subcellular distribution promoted by endogenous opioid peptides differed from the SNC80-induced punctuate internalization pattern, we examined whether receptor localization diverged upon physiological or pharmacological stimulation. Correlative light-electron microscopy showed that the DOReGFP signal was detectable in distinct cellular compartments depending on the mode of receptor activation. As previously described in primary neuronal cultures, DOR-eGFP was detected in multivesicular bodies following SNC80 stimulation, locating delta receptors within the lysosomal degradation pathway (Pradhan et al., 2009). On the other hand, intracellular distribution upon physiological activation identified DOR-eGFP in intracellular vesicles close to synapses. Data therefore suggest that depending on the nature and/or local concentration of the stimulus, the intracellular fate of delta opioid receptors may be affected.
Work by us and others (Ko et al., 1999; Hislop et al., 2009; Pradhan et al., 2009) has documented the predominant lysosomal fate of delta receptors upon drug treatment. In vitro studies, however, also support the potential for delta opioid receptors to enter a recycling pathway based on possible interactions of the receptor with the $\mathrm{N}$-ethylmaleimide-sensitive factor contributing to recycling of the SNARE complex (Zhao et al., 2007). Additionally, serine 363 phosphorylation via the GPCR kinase GRK2 was postulated as a key event favoring delta receptor recycling in heterologous systems (Zhang et al., 2008). Our correlative microscopy data indicate that endogenous stimulation affects the intracellular distribution of the receptor. Further investigations are now required to identify underlying molecular determinants. Though entirely speculative, preferential routing of internalized receptors to a fast recycling pathway after endogenous stimulation represents an attractive hypothesis. It may allow rapid restoration of receptor function and limit receptor degradation that is otherwise observed following drug treatment and lead to tolerance in vivo (Pradhan et al., 2010). The physiological life cycle of the receptor, therefore, likely engages specific molecular mechanisms whose components and dynamics remain to be clarified. DOReGFP mice represent an ideal tool for such investigations, and current work is exploring real-time dynamics of DOR-eGFP internalization in brain slices upon local agonist delivery.

In conclusion, this study demonstrates for the first time that knock-in mice expressing a functional fluorescent GPCR represent a valuable reporter tool to monitor physiological receptor activation. Our results also reveal differences in receptor subcellular distribution upon physiological and pharmacological stimulation, which has important implications for both receptor biology and therapy.

\section{References}

Berrendero F, Castañé A, Ledent C, Parmentier M, Maldonado R, Valverde O (2003) Increase of morphine withdrawal in mice lacking A2a receptors and no changes in CB1/A2a double knockout mice. Eur J Neurosci 17:315-324.

Ciccocioppo R, Martin-Fardon R, Weiss F (2002) Effect of selective blockade of $\mathrm{mu}(1)$ or delta opioid receptors on reinstatement of alcohol-seeking behavior by drug-associated stimuli in rats. Neuropsychopharmacology 27:391-399.

David V, Matifas A, Gavello-Baudy S, Decorte L, Kieffer BL, Cazala P (2008) Brain regional Fos expression elicited by the activation of mu- but not delta-opioid receptors of the ventral tegmental area: evidence for an implication of the ventral thalamus in opiate reward. Neuropsychopharmacology 33:1746-1759.

Decossas M, Bloch B, Bernard V (2003) Trafficking of the muscarinic m2 autoreceptor in cholinergic basalocortical neurons in vivo: differential regulation of plasma membrane receptor availability and intraneuronal localization in acetylcholinesterase-deficient and -inhibited mice. J Comp Neurol 462:302-314.

Enquist J, Kim J, Bartlett S, Ferwerda M, Whistler JL (2011) A novel knock-in mouse reveals mechanistically distinct forms of morphine tolerance. J Pharmacol Exp Ther 338:633-640.

Filliol D, Ghozland S, Chluba J, Martin M, Matthes HW, Simonin F, Befort K, Gavériaux-Ruff C, Dierich A, LeMeur M, Valverde O, Maldonado R, Kieffer BL (2000) Mice deficient for delta- and mu-opioid receptors exhibit opposing alterations of emotional responses. Nat Genet 25:195-200.

Frenois F, Le Moine C, Cador M (2005) The motivational component of withdrawal in opiate addiction: role of associative learning and aversive memory in opiate addiction from a behavioral, anatomical and functional perspective. Rev Neurosci 16:255-276.

Frenois F, Cador M, Caillé S, Stinus L, Le Moine C (2002) Neural correlates of the motivational and somatic components of naloxone-precipitated morphine withdrawal. Eur J Neurosci 16:1377-1389.

Gavériaux-Ruff C, Kieffer BL (2002) Opioid receptor genes inactivated in mice: the highlights. Neuropeptides 36:62-71.

He L, Whistler JL (2011) Chronic Ethanol Consumption in Rats Produces 
Opioid Antinociceptive Tolerance through Inhibition of Mu Opioid Receptor Endocytosis. PLoS One 6:e19372.

Henry AG, White IJ, Marsh M, von Zastrow M, Hislop JN (2011) The role of ubiquitination in lysosomal trafficking of delta-opioid receptors. Traffic 12:170-184.

Hislop JN, Henry AG, Marchese A, von Zastrow M (2009) Ubiquitination regulates proteolytic processing of $\mathrm{G}$ protein-coupled receptors after their sorting to lysosomes. J Biol Chem 284:19361-19370.

Irazusta J, Larrinaga G, Agirregoitia N, Varona A, Casis L (2003) Effects of morphine administration and its withdrawal on rat brain aminopeptidase activities. Regul Pept 110:225-230.

Jung H, Bhangoo S, Banisadr G, Freitag C, Ren D, White FA, Miller RJ (2009) Visualization of chemokine receptor activation in transgenic mice reveals peripheral activation of CCR2 receptors in states of neuropathic pain. J Neurosci 29:8051-8062.

Klausberger T, Somogyi P (2008) Neuronal diversity and temporal dynamics: the unity of hippocampal circuit operations. Science 321:53-57.

Ko JL, Arvidsson U, Williams FG, Law PY, Elde R, Loh HH (1999) Visualization of time-dependent redistribution of delta-opioid receptors in neuronal cells during prolonged agonist exposure. Brain Res Mol Brain Res 69:171-185.

Kouhen OM, Wang G, Solberg J, Erickson LJ, Law PY, Loh HH (2000) Hierarchical phosphorylation of delta-opioid receptor regulates agonistinduced receptor desensitization and internalization. J Biol Chem 275:36659-36664.

Le Merrer J, Plaza-Zabala A, Boca CD, Matifas A, Maldonado R, Kieffer BL (2011) Deletion of the delta Opioid Receptor Gene Impairs Place Conditioning But Preserves Morphine Reinforcement. Biol Psychiatry 69:700-703.

Marinelli PW, Funk D, Harding S, Li Z, Juzytsch W, Lê AD (2009) Roles of opioid receptor subtypes in mediating alcohol-seeking induced by discrete cues and context. Eur J Neurosci 30:671-678.

Martin SJ, Clark RE (2007) The rodent hippocampus and spatial memory: from synapses to systems. Cell Mol Life Sci 64:401-431.

Mátyás F, Freund TF, Gulyás AI (2004) Immunocytochemically defined interneuron populations in the hippocampus of mouse strains used in transgenic technology. Hippocampus 14:460-481.

Noble F, Benturquia N, Bilkei-Gorzo A, Zimmer A, Roques BP (2008) Use of preproenkephalin knockout mice and selective inhibitors of enkephalinases to investigate the role of enkephalins in various behaviours. Psychopharmacology (Berl) 196:327-335.

Nylander I, Vlaskovska M, Terenius L (1995) Brain dynorphin and enkephalin systems in Fischer and Lewis rats: effects of morphine tolerance and withdrawal. Brain Res 683:25-35.

Pascual MM, Pastor V, Bernabeu RO (2009) Nicotine-conditioned place preference induced CREB phosphorylation and Fos expression in the adult rat brain. Psychopharmacology (Berl) 207:57-71.

Pradhan AA, Becker JA, Scherrer G, Tryoen-Toth P, Filliol D, Matifas A,
Massotte D, Gavériaux-Ruff C, Kieffer BL (2009) In vivo delta opioid receptor internalization controls behavioral effects of agonists. PLoS ONE 4:e5425.

Pradhan AA, Walwyn W, Nozaki C, Filliol D, Erbs E, Matifas A, Evans C, Kieffer BL (2010) Ligand-directed trafficking of the delta-opioid receptor in vivo: two paths toward analgesic tolerance. J Neurosci 30:16459-16468.

Rademacher DJ, Napier TC, Meredith GE (2007) Context modulates the expression of conditioned motor sensitization, cellular activation and synaptophysin immunoreactivity. Eur J Neurosci 26:2661-2668.

Rezai X, Faget L, Bednarek E, Schwab Y, Kieffer BL, Massotte D (2012) Mouse Delta Opioid Receptors are Located on Presynaptic Afferents to Hippocampal Pyramidal Cells. Cell Mol Neurobiol 32:506-516.

Robles Y, Vivas-Mejía PE, Ortiz-Zuazaga HG, Félix J, Ramos X, Peña de Ortiz $S$ (2003) Hippocampal gene expression profiling in spatial discrimination learning. Neurobiol Learn Mem 80:80-95.

Rudy JW (2009) Context representations, context functions, and the parahippocampal-hippocampal system. Learn Mem 16:573-585.

Scherrer G, Tryoen-Tóth P, Filliol D, Matifas A, Laustriat D, Cao YQ, Basbaum AI, Dierich A, Vonesh JL, Gavériaux-Ruff C, Kieffer BL (2006) Knockin mice expressing fluorescent delta-opioid receptors uncover G protein-coupled receptor dynamics in vivo. Proc Natl Acad Sci U S A 103:9691-9696.

Schikorski T (2010) Pre-embedding immunogold localization of antigens in mammalian brain slices. Methods Mol Biol 657:133-144.

Taubenfeld SM, Muravieva EV, Garcia-Osta A, Alberini CM (2010) Disrupting the memory of places induced by drugs of abuse weakens motivational withdrawal in a context-dependent manner. Proc Natl Acad Sci U S A 107:12345-12350.

Tejwani GA, Rattan AK (1997) Met-enkephalin alteration in the rat during chronic injection of morphine and/or midazolam. Brain Res 775: $119-126$.

Trafton JA, Abbadie C, Marek K, Basbaum AI (2000) Postsynaptic signaling via the [mu]-opioid receptor: responses of dorsal horn neurons to exogenous opioids and noxious stimulation. J Neurosci 20:8578-8584.

von Zastrow M (2010) Regulation of opioid receptors by endocytic membrane traffic: mechanisms and translational implications. Drug Alcohol Depend 108:166-171.

Zhang X, Wang F, Chen X, Chen Y, Ma L (2008) Post-endocytic fates of delta-opioid receptor are regulated by GRK2-mediated receptor phosphorylation and distinct beta-arrestin isoforms. J Neurochem 106:781792.

Zhao C, Slevin JT, Whiteheart SW (2007) Cellular functions of NSF: not just SNAPs and SNAREs. FEBS Lett 581:2140-2149.

Zheng H, Loh HH, Law PY (2010) Agonist-selective signaling of G proteincoupled receptor: mechanisms and implications. IUBMB Life 62:112119 . 